\title{
Isometric point of lateral femoral condyle analysis with in vitro kinematic study in order to position the extra-articular part of an $\mathrm{ACL}$ reconstruction
}

\author{
M. Ankria , F. Khiami ${ }^{b}$, G. Rochcongar ${ }^{\mathrm{a}, \mathrm{c}}$, T. Joubert ${ }^{\mathrm{a}}$, H. Pillet ${ }^{\mathrm{a}}$, P. Thoreux ${ }^{\mathrm{a}, \mathrm{d}}$ and P. Rouch ${ }^{\mathrm{a}}$ \\ alnstitut de Biomécanique Humaine Georges Charpak Arts et Métiers ParisTech, Paris, France; bPitié-Salpetrière Hospital-Université Paris 6 ,

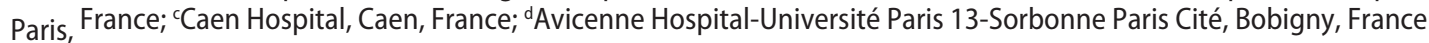

KEYWORDS Extra-articular tenodesis; fascia lata; isometric point; $\mathrm{ACL}$ reconstruction; knee kinematics

\section{Introduction}

The anterior cruciate ligament (ACL) injury leads to an anterior laxity associated with a variable rotational laxity. Without any treatment, this lesion can have functional consequences (instability, disturbance of sport activities or even everyday life activities) and anatomic ones (meniscal or cartilaginous lesions) (Dejour et al. 2004). However, ACL reconstruction can fail in 5-30\% of the cases (Dejour et al. 2004, 2014; Bignozzi et al. 2009), because of a recurrence of laxity or a residual rotational laxity. The extra-articular tenodesis associated with an intra-articular plasty (Khiami et al. 2013) is supposed to control the rotational laxity, but the precise positioning on the lateral femoral condyle is not well defined.

The objective of this study is to determine the isometric point on the lateral side of the lateral femoral condyle relatively to the Gerdy's Tubercle with an in vitro kinematic 3D study.

\section{Methods}

\subsection{Specimens}

12 fresh frozen lower limbs (6 left and 6 right knees) were used in this study. The age was between 47 and 79 years old. The skin and muscles were removed before the experimentation except part of the quadriceps tendon and popliteus muscle. The integrity of the ligaments and the cartilage was inspected at the end of the experimentation during a dissection.

\subsection{Assessment of kinematic data}

The femur was rigidly fixed to the testing rig and the tibia was free to move. A $10 \mathrm{~N}$ force was applied on the quadriceps to coapt the articulation. Cycles of flexion/extension from $0^{\circ}$ to $120^{\circ}$ were made by step of $15^{\circ}$. The extension movement was free; the flexion movement was made with a motor linked to the tibial pilon with a rope. Thus the rotation of the tibia under the femur was also free. In each position, a pair of EOS radiographies was made. After the kinematic testing, the bones were dissected and then scanned separately (CT-scan Philips ICT 256).

\subsection{Database}

The bone borders were reconstructed using Avizo ${ }^{\circledR}$ and then integrated in the EOS pseudo-kinematic to reproduce the flexion movement in 3D. In each position of flexion, the length between the Gerdy's Tubercle and all the points in a defined zone on the lateral femoral condyle was computed with Matlab ${ }^{\otimes}$ by passing over the bone surfaces on the mesh created for scan reconstruction. It allowed us to find the most isometric point of this area relatively to the Gerdy's Tubercle. We made an orthogonal 2D frame (Figure 1) centered on the femoral insertion of the lateral collateral ligament (LCL). The first axis was from distal to proximal within the direction of the femoral shaft and the second one was antero-posterior. The unit used was the distance between the insertion of the LCL and the posterior edge of the lateral condyle, in order to eliminate the inter-individual variations and to use a unit easy to measure in the operating room. We searched the isometric point of the lateral femoral condyle first as the point with the most stable distance to the Gerdy's Tubercle, then we added stretching conditions which were the distance between the position $0^{\circ}$ and $60^{\circ}$ has to be stable or increase up to $15 \%$ (Chan et al. 2010) but not decrease to represent a plasty witch would be stretched and wouldn't slacken at the beginning of the flexion, which is the aim of this surgical technique.

\section{Results and discussion}

The most isometric point we found was in a postero-inferior quadrant, on average at $38 \%$ under and $37 \%$ behind the insertion of the LCL (Figure 1). The average length variation was $4.3 \%$. With the adjunction of the conditions of stretching of the plasty, the isometric point was $36 \%$ under and $40 \%$ behind the LCL (Table 1). The most isometric zone respecting our 


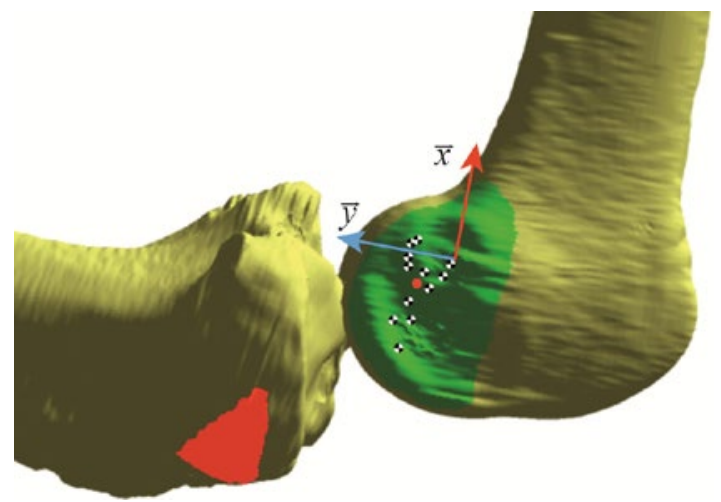

Figure 1. Representation of the repartition of the isometric points found on the 12 knees without stretching conditions (red point: average point, red zone: fascia lata insertion, Gerdy's tubercle considered at the barycenter of this zone, green zone: zone of interest on the lateral femoral condyle).

Table 1. Coordinates of the isometric point and deformation associated.

\begin{tabular}{lcc}
\hline & With no condition & With stretching conditions \\
\hline$x$ (SD) & $-0.38(0.38)$ & $-0.36(0.38)$ \\
$y($ SD) & $0.37(0.17)$ & $0.40(0.16)$ \\
Strain (\%) (SD) & $4.3(2.7)$ & $4.8(2.7)$ \\
\hline
\end{tabular}

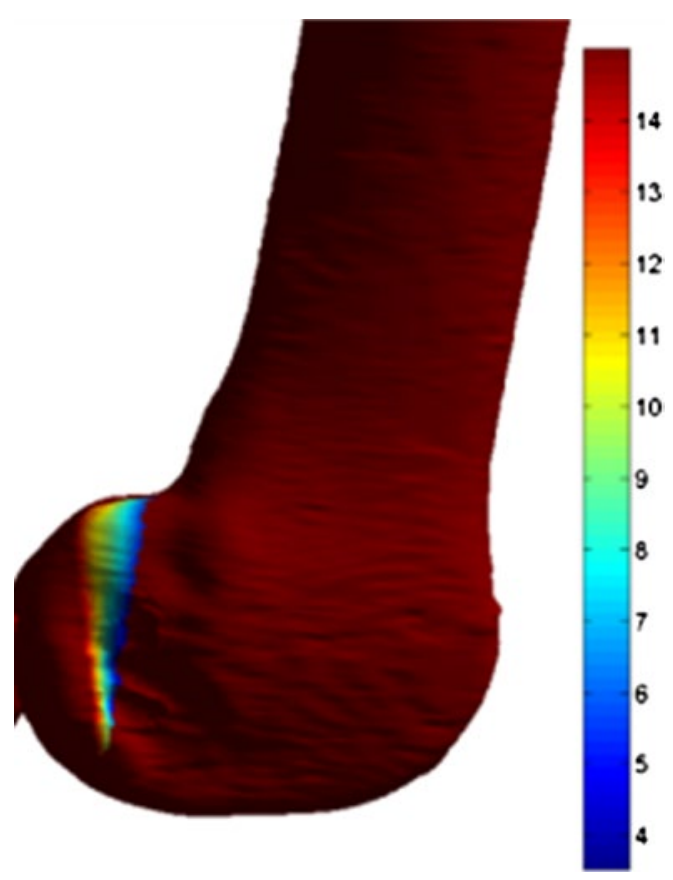

Figure 2. Strain zones (\%) with stretching conditions.

conditions was a tight vertical band running just behind the LCL (Figure 2).

The isometric points we found for all knees tested are more distal than where surgeons use to fix their plasty. We chose to put a low charge on the quadriceps, the extension

\section{Conclusions}

In this in vitro kinematic study, using the last advanced methods of measurement along the bone surfaces, the most isometric point should be behind and under the LCL; there is an almost isometric zone, longitudinal, behind the insertion of the LCL.

\section{Funding}

This work was funded by the SOFCOT (SOciete Francaise de Chirurgie Orthopedique et Traumatologique).

\section{Acknowledgements}

The authors would like to thank Maria Jeyasankar and Sylvain Persohn for their help during the in vitro setup.

\section{References}

Bignozzi S, Zaffagnini S, Lopomo N, Martelli S, Iacono F, Marcacci M. 2009. Does a lateral plasty control coupled translation during anteroposterior stress in single-bundle ACL reconstruction? An in vivo study. Knee Surg Sports Traumatol Arthrosc. 17:65-70.

Chan DB, Temple HT, Latta LL, Mahure S, Dennis J, Kaplan LD. 2010. A biomechanical comparison of fan-folded, single-looped fascia lata with other graft tissues as a suitable substitute for anterior cruciate ligament reconstruction. Arthrosc J Arthrosc Relat Surg. 26:1641-1647.

Dejour D, Neyret P, Dejour H. 2004. Histoire naturelle de la rupture du ligament croisé antérieur [Natural history of anterior cruciate ligament rupture]. In: Landreau P, Christel P, Djian P, editors. Pathol Ligamentaire Genou [Knee ligament pathology]. Paris: Springer; p. 67-80.

Denti M, Randelli P, Bait C, Volpi P. 2014. Revision anterior cruciate ligament reconstruction. In: Bentley G, editor. European Instructional Lectures. Berlin: Springer; p. 183-187.

Draganich LF, Hsieh Y-F, Reider B. 1995. Iliotibial band tenodesis: a new strategy for attachment. Am J Sports Med. 23:186-195.

Khiami F, Wajsfisz A, Meyer A, Rolland E, Catonné Y, Sariali E. 2013. Anterior cruciate ligament reconstruction with fascia lata using a minimally invasive arthroscopic harvesting technique. Orthop Traumatol Surg Res. 99:99-105.

Kittl C, Halewood C, Stephen JM, Gupte CM, Weiler A, Williams A, Amis AA. 2015. Length change patterns in the lateral extra-articular structures of the knee and related reconstructions. Am J Sports Med. 43:354-362.

Krackow KA, Brooks RL. 1983. Optimization of knee ligament position for lateral extraarticular reconstruction. Am J Sports Med. 11:293-302. 